\title{
Estudo da Formação de Ligações Cruzadas por Irradiação Gama em Membranas Híbridas de Polissulfona Bisfenol-A e Sílica Precipitada
}

\author{
Acácio Antonio M. Furtado Filho \\ Laboratório de Química Militar, CTEx
}

\author{
Aílton de S. Gomes, Léa Lopes, Márcia R. Benzi \\ Instituto de Macromoléculas Professora Eloísa Mano, UFRJ
}

\begin{abstract}
Resumo: No presente trabalho a polissulfona bisfenol-A (PSU) foi sulfonada com o agente de sulfonação trimetil silil cloro sulfônico $\left[\left(\mathrm{CH}_{3}\right)_{3} \mathrm{SiSO}_{3} \mathrm{Cl}\right]$, em solução homogênea de dicloroetano. A reação de sulfonação foi confirmada por titulação ácido-base e análises FTIR. As membranas híbridas foram obtidas por vazamento da solução polimérica da polissulfona bisfenol-A sulfonada (SPSU) e sílica precipitada Tixosil ${ }^{\circledR} 333$ em $N$ - $N$-dimetilacetamida (DMAc), e a formação das ligações cruzadas foi estudada por irradiação. Foram utilizadas doses totais de 5 a $30 \mathrm{kGy}$ de radiação gama, oriunda de uma fonte de ${ }^{60} \mathrm{Co}$. A absorção de água foi determinada pela variação percentual da massa da membrana seca e hidratada em água deionizada a 40 e $60{ }^{\circ} \mathrm{C}$. A condutividade protônica das membranas na forma ácida foi obtida pela técnica da espectroscopia de impedância ac utilizando um potenciostato/galvanostato. As membranas híbridas reticuladas por irradiação apresentaram condutividade protônica próxima de $10^{-1} \mathrm{~S}_{\mathrm{cm}} \mathrm{cm}^{-1}$ a $100 \% \mathrm{RH}$ e $80{ }^{\circ} \mathrm{C}$. O desempenho eletroquímico, as estabilidades térmica e mecânica, e o baixo custo tornam a membrana SPSU híbrida reticulada um possível substituto da membrana Nafion nas células a combustível que usam eletrólito polimérico.
\end{abstract}

Palavras-chave: Membrana híbrida, condutividade protônica, irradiação gama, ligações cruzadas.

\section{Study of Cross-linking Reactions Induced by Gamma Rays in Hybrid Membranes of Bisphenol-A-Polysulfone and Precipitated Silica}

\begin{abstract}
In this work the bisphenol-A-polysulfone (PSF) was sulfonated using trimethyl silyl chlorosulfonate $\left[\left(\mathrm{CH}_{3}\right)_{3} \mathrm{SiSO}_{3} \mathrm{Cl}\right]$ as a mild sulfonating agent in a homogeneous solution of dichloroetane. The sulfonation reaction was confirmed by acid-base titration and FTIRspectroscopy analysis. The hybrid membranes were obtained by casting the sulfonated bisphenol-A-polysulfone (SPSF) and precipitated silica Tixosil ${ }^{\circledR} 333$ solutions in $N$-N-dimethylacetamide. Cross-linking in the hybrid membranes was obtained by irradiation, with doses ranging from 5 to $30 \mathrm{kGy}$ using gamma ray from a ${ }^{60} \mathrm{Co}$ source. The water uptake and the swelling of the membranes were estimated by measuring the change in weight between dry and wet conditions. The conductivity of the membranes in acid form was measured with the ac impedance technique using a PGSTAT30 frequency response analyzer. The hybrid cross-linked membranes have conductivity close to $10^{-1}{\mathrm{~S} . \mathrm{cm}^{-1}}$ at $100 \% \mathrm{RH}$ and $80^{\circ} \mathrm{C}$. Electrochemical performances, thermo-mechanical stability and low cost make this cross-linked SPSF hybrid membrane an attractive material for fuel cells using a proton exchange membrane.
\end{abstract}

Keywords: Hybrid membrane, proton conductivity, gamma ray irradiation, cross-linked.

\section{Introdução}

A tecnologia das células a combustível ("Fuel Cell", FC), tem demonstrado que é possível gerar energia de forma eficiente por mecanismos de conversões eletroquímicas, transformando hidrogênio e oxigênio em vapor de água, livre de poluentes, gerando eletricidade e calor. Existem algumas tecnologias de células a combustível que diferem na temperatura operacional, no tipo de combustível e no eletrólito empregado, são elas: célula a combustível a eletrólito polimérico ("Polymer Electrolyte Fuel Cell", PEFC); célula a combustível a metanol direto ("Direct Metanol Fuel Cell", DMFC); célula a combustível alcalina ("Alcaline Fuel Cell”, AFC); célula a combustível ácida ("Phosphoric Acid Fuel Cell", PAFC); célula a combustível a carbonato fundido ("Molten Carbonate Fuel Cell", MCFC) e célula a combustível a óxido sólido ("Solid Oxide Fuel Cell", SOFC). Entretanto, significativo desenvolvimento ainda precisa ser atingido para tornar as células a combustível, técnica e economicamente, competitivas para as mais diversas aplicações ${ }^{[1-3]}$. A célula a combustível a eletrólito polimérico tem se destacado em função da versatilidade na aplicação em veículos automotores e em equipamentos portáteis ${ }^{[3,4]}$. A membrana na PEFC tem função determinante como eletrólito no transporte dos prótons do anodo para o catodo da célula e como barreira para evitar o contato direto entre os gases reagentes $\mathrm{O}_{2}$ e $\mathrm{H}_{2}$, além de apresentar resistência mecânica e estabilidade dimensional na condição hidratada ${ }^{[1,2,5,6]}$. As membranas utilizadas atualmente nas células a combustível são polímeros a base do ácido perfluorosulfônico ("Perfluorosulfonic Acid", PFSA), como a membrana Nafion ${ }^{\circledR}$, desenvolvida pela empresa Du Pont de Nemours ${ }^{[1,7,8]}$. Essas membranas apresentam excelente resistência mecânica, estabilidade em ambientes oxidantes e redutores e alta condutividade protônica na temperatura operacional da célula. Porém, com custo elevado, baixo módulo mecânico, baixa condutividade em temperaturas acima de $80{ }^{\circ} \mathrm{C}$ e elevada permeabilidade ao metanol, observa-se crescimento significativo nos investimentos em pesquisa e desenvolvimento na substituição das membranas perfluoradas ${ }^{[8,10-13]}$.

O presente trabalho tem como objetivo a obtenção da SPSU por meio da reação de sulfonação em meio homogêneo da PSU. A partir da SPSU obtida, fabricar membranas híbridas com a 
sílica precipitada Tixosil ${ }^{\circledR} 333$ e estudar a formação de ligações cruzadas induzidas por radiação gama para obtenção de membranas condutoras de prótons com aplicação em células a combustível a eletrólito polimérico. A formação das ligações cruzadas por irradiação das membranas híbridas SPSU/sílica tem a finalidade de melhorar as propriedades mecânicas, aumentar a estabilidade das membranas ao inchamento em água e melhorar as propriedades de barreira. A sílica amorfa precipitada Tixosil ${ }^{\circledR} 333$ apresenta como estrutura química básica $10 \mathrm{SiO}_{2} \cdot 1 \mathrm{H}_{2} \mathrm{O}$, com subunidades de silicato $\left(\mathrm{SiO}_{4}\right)$ dispostas de forma irregular na sua estrutura ${ }^{[6,9]}$.

Existem dois tipos de radiações aplicadas nas modificações poliméricas, a radiação ionizante de baixa densidade, como o raio $\mathrm{X}$, o feixe de elétrons e os raios gama, e a radiação ionizante de alta densidade, como os íons pesados acelerados ${ }^{[14,15]}$. A energia envolvida nas radiações ionizantes mais baixas (20-30 eV) é muito maior do que a energia das ligações químicas presentes nas moléculas orgânicas (3-5 eV). Assim, a energia disponível excede bastante a necessária para quebrar qualquer ligação química. As quebras das ligações seguem algumas regras de seletividade, que ainda não estão bem estabelecidas, e não ocorrem de forma aleatória. Nos hidrocarbonetos lineares, as ligações $\mathrm{C}-\mathrm{H}$ são quebradas com maior frequência do que as ligações $\mathrm{C}-\mathrm{C}$. Ácido carboxílico gera elevado rendimento de $\mathrm{CO}_{2}$, amina gera $\mathrm{NH}_{3}$. A presença de cloretos torna o material mais sensível à radiação, enquanto grupamentos aromáticos tendem a proteger a molécula. Dessa forma, o efeito da radiação sobre as ligações químicas, provoca mudanças nas propriedades físicas dos materiais poliméricos ${ }^{[16]}$. As reações iniciadas pela radiação podem ser classificadas em dois tipos: (I) formação de ligações cruzadas ou reticulação e cisão da cadeia principal, e (II) ramificação ou graftização ${ }^{[16,17]}$. Na reticulação ocorre a formação de ligações intermoleculares entre as cadeias do polímero. O grau de reticulação é proporcional à dose de radiação e não requer insaturação ou outros grupos reativos na cadeia. Com algumas exceções, como nos polímeros aromáticos, não varia muito com a estrutura química $^{[18,19]}$. O mecanismo envolve a quebra de uma ligação $\mathrm{C}-\mathrm{H}$ de uma cadeia polimérica para formar um átomo de hidrogênio, seguido pela abstração de um segundo átomo de hidrogênio de uma cadeia vizinha e formação de hidrogênio molecular. Os dois radicais poliméricos adjacentes se combinam para formar uma ligação cruzada ${ }^{[20-22]}$. O efeito da reticulação é a formação de uma rede polimérica tridimensional e um acentuado aumento no peso molecular. O processo oposto a reticulação é a cisão ou quebra da cadeia principal, na qual, sob ação da energia de radiação, ocorre a quebra de ligações $\mathrm{C}-\mathrm{C}$, levando à redução do peso molecular médio e a degradação do polímero ${ }^{[9,17]}$. Na modificação polimérica por irradiação em solução, o solvente possui a função de promover o inchamento da matriz polimérica, e assim aumentar a mobilidade das cadeias nas camadas internas do polímero, favorecendo a sua interação com os sítios ativos, levando a graus de reticulação mais elevados ${ }^{[23,24]}$. Mecanismos de formação das ligações cruzadas têm sido propostos para a PSU, através de ligações-H nos grupamentos isopropilidenos e ligações-Y, ou ligações terminais, por meio dos grupamentos aromáticos. A ligação-H é formada quando duas espécies da cadeia principal, geralmente radicais livres, ficam muito próximas e reagem. As estruturas das ligações-H são muito rígidas, restringindo a reorientação e a mobilidade da cadeia principal, afetando a resistência do polímero. As ligações-Y podem ser formadas através de dois caminhos: (i) ligação entre uma dupla ligação terminal de cadeia e um macroradical; (ii) adição de um grupamento terminal reativo, formado pela quebra da cadeia, a uma cadeia polimérica próxima ${ }^{[20]}$. Os polímeros que apresentam ligações-Y possuem maior mobilidade das cadeias, para o mesmo número de pontos de ramificação em relação aos polímeros que possuem somente ligações-H, levando a uma maior resistência à fratura e menor degradação das propriedades mecânicas para a mesma densidade de ligações cruzadas ${ }^{[20,21]}$.

\section{Experimental}

\section{Sulfonação da Polissulfona Bisfenol-A (PSU)}

A reação de sulfonação da PSU foi processada em câmara de luvas com umidade controlada abaixo de $10 \mathrm{ppm}$. A PSU pura foi adicionada a balão volumétrico de três vias para solubilização no solvente 1,2 dicloroetano (DCE). Na entrada central do balão foi feita a adição do agente de sulfonação trimetil silil cloro sulfônico $\left[\left(\mathrm{CH}_{3}\right)_{3} \mathrm{SiSO}_{3} \mathrm{Cl}\right]$ (TMSCS) solubilizado em parte do solvente. Nas vias laterais do balão foi adaptado um termômetro, para controle da temperatura, e a entrada do gás de arraste (argônio) do $\mathrm{HCl}$ formado durante a reação. $\mathrm{O}$ sistema foi mantido sob aquecimento e agitação magnética durante todo o processo. Após o término da reação, o material obtido foi precipitado em isopropanol em baixa temperatura sob agitação mecânica. $\mathrm{O}$ precipitado foi lavado com isopropanol para eliminação do ácido residual com controle do $\mathrm{pH}$ do meio ${ }^{[5]}$. Posteriormente o polímero foi seco em estufa a vácuo $\left(-760 \mathrm{~mm} \cdot \mathrm{Hg}^{-1}\right)$ a $80^{\circ} \mathrm{C}$ por 24 horas.

\section{Fabricação das membranas híbridas}

As membranas híbridas foram obtidas pelo processo de vazamento. A solução polimérica foi preparada a $18 \%$ massa/ volume com adição de 5\% em massa da sílica amorfa precipitada Tixosil $^{\circledR} 333$ no solvente DMAc. A solução foi mantida sob agitação magnética e aquecimento a $60{ }^{\circ} \mathrm{C}$, e processado o vazamento sobre superfície de vidro plano no interior de limitadores de superfície. $\mathrm{O}$ sistema foi mantido nivelado no interior de estufa aquecida a $50{ }^{\circ} \mathrm{C}$ durante 12 horas, com atmosfera saturada do solvente para a perfeita formação do filme. Posteriormente as membranas foram extraídas do vidro e secas em estufa a vácuo $\left(-760 \mathrm{~mm} \cdot \mathrm{Hg}^{-1}\right)$ a $80{ }^{\circ} \mathrm{C}$ até peso constante ${ }^{[5]}$.

\section{Reação de reticulação das membranas híbridas com radiação gama}

As membranas híbridas secas foram pesadas e imersas em água deionizada em reator de vidro. No reator lacrado foi criada atmosfera inerte de $\mathrm{N}_{2}$. As amostras foram irradiadas no Laboratório de Instrumentação Nuclear da COPPE, na temperatura ambiente e pressão atmosférica, utilizando o equipamento MDS Nordion modelo Gammacell 220 Excel. A taxa da dose de radiação empregada foi de $55,0 \mathrm{~Gy} / \mathrm{min}$. O tempo da irradiação das amostras foi calculado em função da taxa e a dose total de radiação. O processo da irradiação foi monitorado com auxílio de dosímetros. Após a irradiação, as membranas SPSU foram tratadas termicamente em estufa a vácuo a $120{ }^{\circ} \mathrm{C}$ por 2 horas para eliminação dos radicais residuais.

\section{Espectroscopia de Infravermelho por Transformada de Fourier (FTIR)}

Os ensaios FTIR-ATR foram realizados nas membranas poliméricas híbridas original e irradiadas com doses totais de 5, 10, 15, e 20 kGy em equipamento Perkin Elmer, modelo FTIR 1720-X, com dispositivo ATR (Attenuated Total Reflectance) acoplado. Os espectros foram coletados na região entre 4000 e $450 \mathrm{~cm}^{-1}$, com varredura de 50 e resolução de $2 \mathrm{~cm}^{-1[25]}$.

\section{Espalhamento de raios $X$ em altos ângulos (WAXS)}

A técnica do espalhamento de raios X em altos ângulos (WAXS) permite a caracterização dos componentes dos materiais e também 
a obtenção de informações sobre o estado cristalino e amorfo do material. As medidas do espalhamento de raios $\mathrm{X}$ foram realizadas em equipamento Miniflex fabricado pela empresa Rigaku com tubo de cobre $(\mathrm{CuK} \alpha$, comprimento de onda $\lambda=1,5418 \AA$ e um monocromador de grafite, a uma velocidade de $0,05 \% \mathrm{~min}$ com $2 \theta$ variando de 5 a $80^{\circ}$. A Lei ou Equação de Bragg estabelece a condição essencial para que ocorra a difração e é dada pela Equação 1.

$$
\mathrm{n} \lambda=2 \mathrm{~d} \operatorname{sen} \theta
$$

Onde:

- $\mathrm{n}$ = ordem da reflexão e é igual ao número de comprimentos de onda contido na diferença de caminho entre os raios espalhados por planos adjacentes;

- $\lambda=$ comprimento de onda dos do feixe incidente de raios $\mathrm{X}$ $(1,541 \AA)$;

- $\mathrm{d}=$ distância interplanar;

- $\theta=$ metade do ângulo de espalhamento.

\section{Propriedades das membranas condutoras de prótons}

Capacidade de Troca lônica (IEC) e Grau de Sulfonação (GS)

A capacidade de troca iônica (IEC) foi determinada pelo método da titulação. As membranas na forma ácida $\left(\mathrm{H}^{+}\right)$foram imersas em solução aquosa de $\mathrm{NaCl}$ por 24 horas a $60^{\circ} \mathrm{C}$ sob agitação magnética para a liberação do $\mathrm{H}^{+}$. A quantidade de $\mathrm{H}^{+}$liberada na solução de $\mathrm{NaCl}$ foi titulada com solução $0,05 \mathrm{~mol} / \mathrm{L}$ de $\mathrm{NaOH}$ até $\mathrm{pH}=7$, utilizando azul de bromo timol como indicador. O IEC ( $\mathrm{mol} / \mathrm{g})$ foi calculado utilizando a Equação 2 ${ }^{[20,21]}$ :

$$
\mathrm{IEC}=\frac{\left(0,05 \times \mathrm{vol}_{\mathrm{NaOH}}\right)}{\mathrm{M}}
$$

onde o $\mathrm{Vol}_{\mathrm{NaOH}}$ é o volume de $\mathrm{NaOH}(\mathrm{L})$ consumido na titulação e $\mathrm{M}$ (g) é a massa da amostra da membrana seca. O Grau de sulfonação (GS) indica a quantidade de grupamentos de ácido sulfônico por unidade monomérica e é calculado por meio da Equação $3^{[26,27]}$ :

$$
\mathrm{GS}=\frac{(442 \times \mathrm{IEC})}{[1-(80 \times \mathrm{IEC})]}
$$

onde 442 e 80 são os pesos moleculares do PSU e do grupamento $-\mathrm{SO}_{3}^{-}$, respectivamente.

\section{Estabilidade Química (EQ)}

A estabilidade química ou estabilidade oxidativa, foi determinada por imersão de amostras das membranas com as dimensões $1,5 \times 1,5 \mathrm{~mm}$ e $100 \mu \mathrm{m}$ de espessura, no reagente de Fenton ( $3 \%$ de $\mathrm{H}_{2} \mathrm{O}_{2}$ contendo $2 \mathrm{ppm}$ de $\mathrm{FeSO}_{4}$ ) a $80{ }^{\circ} \mathrm{C}$. A estabilidade química das amostras foi caracterizada como o intervalo de tempo decorrido até a completa dissolução da amostra no reagente ${ }^{[27,28]}$.

\section{Grau de Inchamento (Gl)}

$\mathrm{O}$ grau de inchamento no equilíbrio das membranas foi determinado em água deionizada a 40 e $60{ }^{\circ} \mathrm{C}$ por 24 horas. Amostras das membranas $(1,5 \times 1,5 \mathrm{~mm}$ e $100 \mu \mathrm{m}$ de espessura $)$ foram imersas em água deionizada. A pesagem a úmido $(\mathrm{Pu})$ foi feita em intervalos de uma hora após a retirada do excesso de água da superfície da membrana com material absorvente. O peso da membrana seca (Ps) foi determinado após secagem em estufa a vácuo a $80{ }^{\circ} \mathrm{C}$ por 24 horas. $\mathrm{O}$ grau de inchamento foi calculado de acordo com a Equação $4^{[29,30] \text { : }}$

$$
\text { GI }(\%)=\frac{\left(\mathrm{P}_{\mathrm{U}}-\mathrm{P}_{\mathrm{S}}\right)}{\mathrm{PS} \times 100}
$$

\section{Condutividade protônica das membranas poliméricas}

A condutividade protônica das membranas foi determinada pelo método da espectroscopia de impedância. O sistema de medidas consiste de uma célula eletroquímica com dois eletrodos de aço inox circulares e área superficial efetiva de $1,0 \mathrm{~cm}^{2}$, uma estufa para o aquecimento do conjunto e um potenciostato/galvanostato modelo Autolab PGSTAT 30, com módulo de análise de resposta de frequência ("Frequency Response Analysis", FRA). O potenciostato trabalha com oscilação de potencial de $10 \mathrm{mV}$ na faixa de frequência de $10.0 \mathrm{~Hz}$ a $1.0 \mathrm{Mhz}^{[31,32]}$.

As membranas foram prensadas entre dois eletrodos planos, a base de carbono impregnado com platina (E-TEK ${ }^{\circledR}$ Eletrodo). $\mathrm{O}$ ensaio da condutividade foi realizado na direção transversal da membrana. Previamente ao ensaio as membranas foram tratadas com solução de $\mathrm{HCl} 0,1 \mathrm{~N}$ a $80{ }^{\circ} \mathrm{C}$ por uma hora. Os ensaios da espectroscopia de impedância foram realizados na temperatura de $30{ }^{\circ} \mathrm{C}$ e na temperatura operacional da célula a combustível a eletrólito polimérico $\left(80^{\circ} \mathrm{C}\right)$. As curvas Nyquist foram obtidas após a estabilização das membranas no ensaio, esse tempo leva uma hora para o ensaio a $30^{\circ} \mathrm{C}$ e três horas para o ensaio a $80^{\circ} \mathrm{C}$. A interseção inferior da curva com o eixo $\operatorname{Re}(Z)$ fornece o valor da resistência da membrana (R). A condutividade protônica das membranas foi calculada de acordo com a Equação $5^{[31,33]}$ :

$$
\sigma=\frac{\mathrm{L}}{\mathrm{RA}}
$$

onde $\sigma$ é condutividade protônica, L a espessura da membrana hidratada, $\mathrm{R}$ a resistência da membrana e $\mathrm{A}$ a área do eletrodo.

\section{Resultados e Discussão}

\section{Reação de sulfonação}

Na reação de sulfonação da PSU as concentrações do agente de sulfonação e do polímero foram mantidas constantes em 30 e $10 \%$ em massa, respectivamente. Alterações nas condições reacionais como temperatura, tempo e razão molar entre o agente de sulfonação e a unidade monomérica $(\mathrm{X})$, permitiram a obtenção de polímeros com diferentes valores no grau de sulfonação e diferentes propriedades (Tabela 1) ${ }^{[34]}$.

A amostra SPSU01 foi sintetizada com a menor razão molar entre o agente de sulfonação e a unidade monomérica e gerou baixo GS. Analisando a Tabela 2, observamos que a amostra SPSU02 apresentou o menor valor do GS entre as amostras analisadas, gerando baixo GI e condutividade protônica. A membrana fabricada com esse material apresentou o melhor resultado da EQ. Esse comportamento está associado à baixa temperatura reacional $\left(30{ }^{\circ} \mathrm{C}\right)$. O fator temperatura fica mais evidente quando analisamos as sínteses SPSU03 e SPSU04, onde observamos aumento significativo do GS com o aumento da temperatura ${ }^{[34]}$.

A síntese SPSU05 foi processada no maior tempo de reação (24 horas), e gerou resultados muito semelhantes à síntese SPSU04

Tabela 1. Condições da reação de sulfonação da polissulfona bisfenol-A.

\begin{tabular}{lcccc}
\hline Amostra & $\mathbf{X}$ & $\begin{array}{c}\text { Temperatura } \\
\left({ }^{\circ} \mathbf{C}\right)\end{array}$ & $\begin{array}{c}\text { Tempo } \\
(\mathbf{h})\end{array}$ & $\begin{array}{c}\text { Rendimento } \\
(\boldsymbol{\%})\end{array}$ \\
\hline SPSU01 & 1,00 & 50,0 & 5 & 83,90 \\
SPSU02 & 1,35 & 30,0 & 5 & 95,30 \\
SPSU03 & 1,35 & 40,0 & 5 & 89,00 \\
SPSU04 & 1,35 & 70,0 & 5 & 87,60 \\
SPSU05 & 1,35 & 50,0 & 24 & 83,39 \\
SPSU06 & 2,00 & 50,0 & 5 & 84,40 \\
\hline
\end{tabular}

$\mathrm{X}$ - razão molar entre o agente de sulfonação e a unidade monomérica. 
que foi processada em cinco horas na temperatura de $70{ }^{\circ} \mathrm{C}^{[7,9]}$ $\mathrm{O}$ aumento da razão molar entre os reagentes (SPSU06) gerou membrana com os maiores valores do GS, da condutividade protônica e do GI, porém, apresentou a menor EQ. Esses resultados indicam que essa membrana é muito instável, inviabilizando sua utilização nas células a combustível de elevada temperatura ${ }^{[7,33,34]}$.

As membranas condutoras de prótons a base de polímeros aromáticos sulfonados apresentam valor crítico do grau de sulfonação, abaixo do qual a condutividade protônica fica muito prejudicada. A redução da densidade dos grupamentos sulfônicos prejudica a conectividade entre os domínios hidrofílicos dificultando a condutividade protônica ${ }^{[11,12]}$. No caso das membranas SPSU, o valor crítico do GS está próximo de $45 \%$ porque a síntese SPSU02, que apresentou o menor valor do GS (46\%), apresentou também os menores valores da condutividade, além de não ter sido observada diferença significativa da condutividade protônica entre as duas temperaturas avaliadas $\left(30 \text { e } 80^{\circ} \mathrm{C}\right)^{[34,35]}$.

\section{Reação de reticulação das membranas híbridas}

A técnica escolhida para avaliar a reação de reticulação das membranas híbridas por irradiação foi o aumento gradativo da dose total da radiação aplicada às membranas e a avaliação das propriedades de inchamento, grau de sulfonação, condutividade protônica e estabilidade química após a irradiação. Quando submetidas à radiação gama, as ligações sulfônicas são quebradas, ocorre formação de radicais positivos nos anéis benzênicos e liberação de ácido sulfúrico $\left(\mathrm{H}_{2} \mathrm{SO}_{4}\right)$. Os radicais livres nos anéis benzênicos se combinam com grupos sulfônicos de moléculas adjacentes para formar ligações cruzadas. Segundo esse mecanismo, o aumento da densidade das ligações cruzadas reduz o número de sítios ativos susceptíveis à dissociação iônica e, consequentemente, a condutividade protônica das membranas ${ }^{[35]}$.

Conforme a Tabela 3, os resultados do GS e IEC das membranas híbridas irradiadas, apresentam tendência de redução gradual com o aumento da dose total da radiação. Os resultados do grau de inchamento em água não apresentaram alterações significativas com o aumento da dose, sendo que os valores encontrados na temperatura de $60{ }^{\circ} \mathrm{C}$ são cerca de $50 \%$ maiores do que os valores a $40{ }^{\circ} \mathrm{C}$. Quando ocorre aumento da temperatura, aumenta também a mobilidade das cadeias poliméricas e o volume livre para absorção de água, resultando no aumento do grau de inchamento.

As condutividades protônicas, avaliadas a 30 e $80^{\circ} \mathrm{C}$, apresentam tendência de redução gradual com aumento da dose total de radiação, com os maiores valores determinados na temperatura de $80{ }^{\circ} \mathrm{C}$ (Figura 1). Nessa temperatura foi observada redução acentuada nas doses mais elevadas, indicando mudança de comportamento a partir da dose de $25 \mathrm{kGy}$. Os resultados da estabilidade química das membranas híbridas irradiadas foram muito superiores em relação à membrana SPSU04 original (entre 49 e 109\%). Esses resultados indicam evolução da resistência das membranas híbridas. Entretanto, a estabilidade química apresenta tendência de redução acentuada a partir da dose de $25 \mathrm{kGy}$. Esse comportamento indica que essas membranas híbridas tendem a sofrer degradação quando submetidas a doses de radiação acima de 20 kGy.

\section{Espalhamento de raios $X$ a altos ângulos (WAXS) das membranas híbridas}

As curvas de espalhamentos de raios X a altos ângulos (WAXS) das membranas SPSU04 original e SPSU04 híbridas com 5\% da sílica Tixosil ${ }^{\circledR} 333$ irradiadas com 5, 25 e 30 kGy de dose total de radiação gama são apresentadas na Figura 2 .

Os resultados apresentam padrão típico de polímeros amorfos. As membranas SPSU04 original e híbrida irradiada com 5 kGy
Tabela 2. Propriedades das membranas SPSU, GS (\%), GI (\%) avaliado a $40{ }^{\circ} \mathrm{C}, \sigma\left(\mathrm{mS} \mathrm{cm}^{-1}\right)$ a 30 e $80{ }^{\circ} \mathrm{C}$, IEC (meq. $\left.{ }^{-1}\right)$ e EQ (minute).

\begin{tabular}{|c|c|c|c|c|c|c|}
\hline \multirow[t]{2}{*}{ Amostra } & \multirow{2}{*}{$\begin{array}{l}\text { GS } \\
(\%)\end{array}$} & \multirow{2}{*}{$\begin{array}{l}\text { GI } \\
(\%)\end{array}$} & \multicolumn{2}{|c|}{$\sigma\left(\mathbf{m S} . \mathrm{cm}^{-1}\right)$} & \multirow{2}{*}{$\begin{array}{c}\text { IEC } \\
(\text { meq.g } \\
\left.\text { g }^{-1}\right)\end{array}$} & \multirow{2}{*}{$\begin{array}{c}\text { EQ } \\
\text { (minutes) }\end{array}$} \\
\hline & & & $30^{\circ} \mathrm{C}$ & $80^{\circ} \mathrm{C}$ & & \\
\hline SPSU01 & 54,7 & 18,2 & 20,0 & 42,0 & 1,126 & 83 \\
\hline SPSU02 & 46,0 & 4,0 & 6,0 & 6,6 & 0,961 & 150 \\
\hline SPSU03 & 70,6 & 17,1 & 32,4 & 70,7 & 1,416 & 79 \\
\hline SPSU04 & 75,2 & 30,2 & 30,6 & 98,7 & 1,498 & 78 \\
\hline SPSU05 & 75,0 & 32,2 & 77,5 & 88,4 & 1,494 & 20 \\
\hline SPSU06 & 83,4 & 85,8 & 89,0 & NR & 1,639 & 6 \\
\hline
\end{tabular}

GS - Grau de sulfonação; GI-Grau de inchamento; $\sigma$-Condutividade protônica; IEC - Capacidade de troca iônica; EQ - Estabilidade química; NR - A membrana não resistiu.

Tabela 3. Propriedades das membranas SPSU04 híbridas com 5\% da sílica precipitada Tixosil ${ }^{\otimes} 333$, irradiadas nas doses totais de 5, 10, 15, 20, 25 e 30 kGy: GS (\%), GI (\%) a 40 e $60^{\circ} \mathrm{C}, \sigma\left(\mathrm{mS} \mathrm{cm}^{-1}\right)$ a 30 e $80^{\circ} \mathrm{C}$, IEC (meq.g $\left.{ }^{-1}\right)$ e EQ (minutes).

\begin{tabular}{|c|c|c|c|c|c|c|c|}
\hline \multirow{2}{*}{$\begin{array}{l}\text { Dose } \\
\text { (kGy) }\end{array}$} & \multirow{2}{*}{$\begin{array}{c}\text { GS } \\
(\%)\end{array}$} & \multicolumn{2}{|c|}{ GI (\%) } & \multicolumn{2}{|c|}{$\sigma\left(\mathbf{m S} . \mathbf{c m}^{-1}\right)$} & \multirow{2}{*}{$\begin{array}{c}\text { IEC } \\
\left(\text { meq. }{ }^{-1}\right)\end{array}$} & \multirow{2}{*}{$\begin{array}{c}\text { EQ } \\
\text { (minutes) }\end{array}$} \\
\hline & & $40^{\circ} \mathrm{C}$ & $60^{\circ} \mathrm{C}$ & $30^{\circ} \mathrm{C}$ & $80^{\circ} \mathrm{C}$ & & \\
\hline 5 & 59,0 & 31,5 & 48,4 & 64,4 & 94,2 & 1,216 & 15,0 \\
\hline 10 & 56 & 28,7 & 43,6 & 5 & & 16 & 5 \\
\hline 15 & 51,7 & 28,8 & & & & , & \\
\hline 20 & 52,6 & 28,2 & 44,3 & 27,9 & 61 & 08 & 1635 \\
\hline 25 & 50,3 & 27,4 & 43,1 & 24,7 & 27,6 & 1,042 & 116,0 \\
\hline 30 & 50,5 & 29,3 & 44,7 & 19,7 & 33,6 & 1,046 & 122,5 \\
\hline
\end{tabular}

GS - Grau de sulfonação; GI-Grau de inchamento; $\sigma$-Condutividade protônica; IEC - Capacidade de troca iônica; EQ - Estabilidade química.

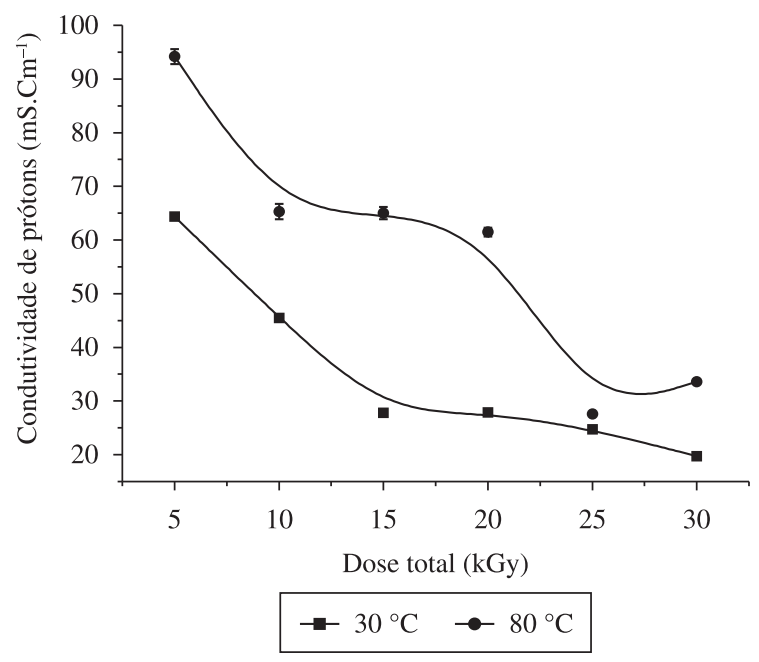

Figura 1. Condutividade protônica $\left(\mathrm{mS} . \mathrm{cm}^{-1}\right)$ das membranas híbridas em função da dose total de radiação (kGy), avaliadas nas temperaturas de 30 e $80{ }^{\circ} \mathrm{C}$.

apresentam curvas muito semelhantes com o surgimento de halos amorfos em $2 \theta$ ao redor de $6^{\circ}, 28^{\circ}$ e $44^{\circ}$. Com o aumento da dose total de radiação para 25 e $30 \mathrm{kGy}$ ocorre deslocamento do halo intermediário para ângulos mais baixos, bem característico da sílica pura, além do aumento significativo da sua intensidade. Esse comportamento indica a influência do processo da irradiação nas membranas híbridas, promovendo um rearranjo entre as cadeias poliméricas e a fase inorgânica da sílica, justificando a mudança de comportamento da condutividade protônica a $80^{\circ} \mathrm{C}$ e da estabilidade química nas doses de radiação de 25 e 30 kGy. 


\section{Espectroscopia de Infravermelho por Transformada de Fourier (FTIR) das membranas hibridas}

A Figura 3 apresenta os espectros FTIR-ATR das membranas híbridas na forma ácida irradiadas com doses de 5, 10, 15, e 20 kGy com radiação gama.

Os espectros apresentados na Figura 3 são característicos da polissulfona bisfenol-A sulfonada. A banda na frequência $875 \mathrm{~cm}^{-1}$ é característica da deformação fora do plano nos anéis aromáticos. A banda a $1014 \mathrm{~cm}^{-1}$ está associada à vibração do anel aril-éter p-substituído e é considerado um bom padrão interno porque não sofre alterações com a irradiação em função da proteção do anel aromático ${ }^{[33,35]}$. A banda a $1169 \mathrm{~cm}^{-1}$ está associada às vibrações dos estiramentos assimétricos dos grupamentos sulfônicos. Mesmo após o processo da irradiação, não são observadas alterações na intensidade dessa banda nos espectros das amostras analisadas em comparação com o padrão interno. Esse comportamento é um indicativo que ocorre preservação dos grupamentos sulfônicos das membranas com a irradiação. A banda a $1238 \mathrm{~cm}^{-1}$ está associada ao estiramento assimétrico dos grupamentos aril-éter $(\mathrm{C}-\mathrm{O}-\mathrm{C})^{[36-39]}$.
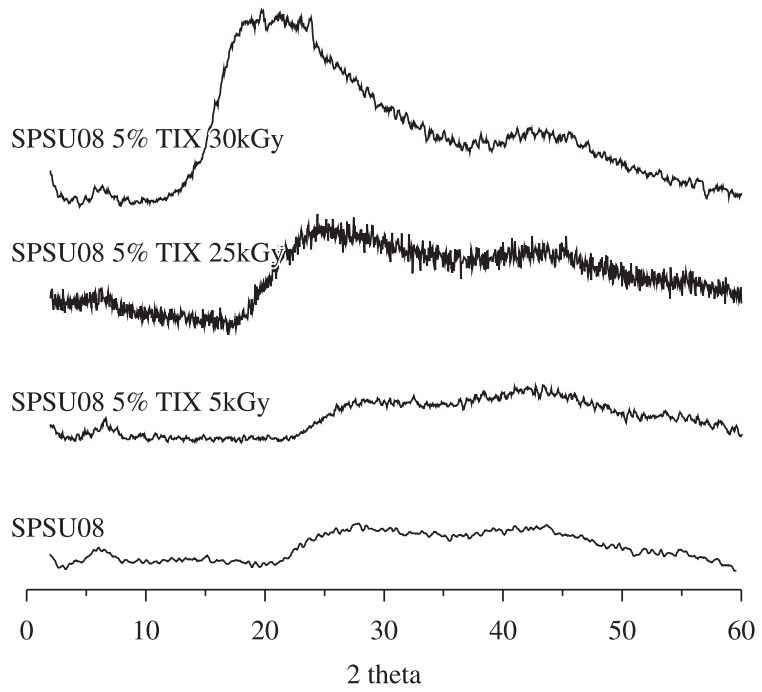

Figura 2. Difratograma WAXS membranas SPSU04 original e híbridas com $5 \%$ da sílica Tixosil ${ }^{\circledR} 333$ irradiadas com doses de 5, 25 e 30 kGy.

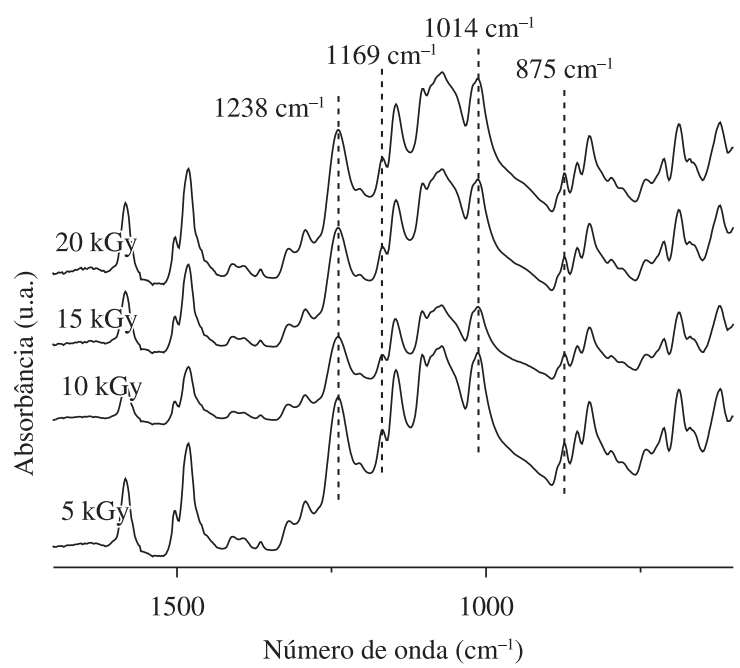

Figura 3. FTIR-ATR das membranas híbridas com 5\% de sílica Tixosil ${ }^{\circledR}$ 333 , irradiadas com raios gama com doses de 5, 10, 15 e $20 \mathrm{kGy}$.

\section{Conclusão}

A reação de sulfonação da PSU com o agente de sulfonação TMSCS determina a qualidade da membrana de partida na modificação por irradiação. A obtenção da SPSU, com graus de sulfonação variando entre 46 e $83 \%$, foi confirmada por meio da titulação ácido/base e da caracterização pela técnica FTIR. O estudo da reticulação por irradiação gama das membranas SPSU híbridas com sílica precipitada Tixosil ${ }^{\circledR} 333$ nas doses totais de até $30 \mathrm{kGy}$ comprovou que o GS, a IEC e a condutividade protônica, nas duas temperaturas analisadas, sofreram redução gradual com aumento da dose total da radiação. O GI das membranas híbridas irradiadas não sofreu alteração significativa com o aumento da dose. O tempo da estabilidade química ao reagente de Fenton das membranas híbridas aumentou de forma acentuada em relação à membrana original. Dessa forma, a reticulação por irradiação das membranas SPSU aponta para um caminho promissor na substituição das membranas perfluoradas para utilização como membrana condutora de prótons em célula a combustível.

\section{Agradecimentos}

Os autores agradecem aos órgãos de fomento CNPq e CAPES pelo apoio financeiro, à empresa BASF pelo fornecimento do PSU, e ao Professor Edgar Francisco de Jesus do Laboratório de Instrumentação Nuclear da COPPE pela irradiação.

\section{Referências Bibliográficas}

1. Böddeker, K. W.; Peinemann, K. V. \& Nunes, S. P. - J. Memb. Sci, 185, p.1 (2001).

2. Bruijn, F. A.; Dam, V. A. T.; Janssen, G. J. M. - Fuel Cells, 08 p.3 (2008).

3. Borup, R. et al. - Chem. Rev., 107, p.3904 (2007).

4. Hotza, D. \& Costa, J. C. D. - Hydrogen Energy, 33, p.4915 (2008).

5. Lufrano, F.; Squadrito, S.; Patti, A.; Passalacqua, E.- J. Appl. Polym. Sci., 77, p.1250 (2000).

6. Kerres, J. A. - J. Memb. Sci., 185, p.3 (2001).

7. Rikukaua, M. \& Sanui, K. - Progr. Polym. Sci., 25, p.1463 (2000).

8. Manea, C.; Mulder, M. - J. Memb. Sci., 206, p.443 (2002).

9. Murakami, K. \& Kudo, H. - Nucl. Instr. Meth. Phys. Res. B., 265, p.125 (2007)

10. Wang, F.; Hickner, M.; Kim, Y. S.; Zawodzinski, T. A.; McGrath, J. E. - J. Memb. Sci, 197, p.231, (2002).

11. Karlsson, L. E. \& Jannasch, P. - J. Memb. Sci., 230, p.61 (2004).

12. Karlsson, L. E. \& Jannasch, P. - Electroch. Acta, 50, p.1939 (2005).

13. Park, Y. \& Yamazaki, Y. - Polym. Bull., 53, p.181 (2005).

14. Tager, A. - Phys. Chem. Polym., p.338 (1978).

15. Clough, L. R. - Nucl. Instr. Meth. Phys. Res. B., 185, p.8 (2001).

16. Bhattacharya, A. - Progr. Polym. Sci., 25, p.371 (2000).

17. Reichmanis, E.; Frank, C. W.; O’Donnell, J. H.; Hill, D. J. T. - ACS Symposium Series, 527, p.1 (1993).

18. Sasuga, T.; Kudoh, H. \& Seguchi, T. - Polymer, 40, p.5095 (1999).

19. Izumi, Y.; Nagaike, H.; Tabuse, S.; Yoshida, Y. \& Tagawa, S. - Rad. Phys. Chem., 62, p.83 (2001).

20. El-Sayed, A.; Hegazy, E. A.; Sassuga, T.; Nishii, M. \& Seguchi, T. Polymer, 33, p.2897 (1992).

21. Hill, D. J. T.; Lewis, D. A.; Donnell, J. H. \& Whittaker, A. K. - Polym. Adv Technol., 9, p.45 (1998).

22. Gupta, B.; Bfichi, F. N.; Scherer, G. G. \& Chapiro, A. - Solid State Ion., 61, p.213 (1993). 
23. Nasef, M. M.; Saidi, H. \& Yarmo, M. A. - J. Appl. Polym. Sci., 76, p.336 (2000).

24. Nasef, M. M.; Saidi, H.; Nor, H. M. - J. Appl. Polym. Sci., 78, p.2443 (2000).

25. Silverstein, R. M.; Bassler, G. C.; Morrill, T. C. - "Identificação espectrométrica de compostos orgânicos", Guanabara Koogan, Rio de Janeiro (1994).

26. Guan, R.; Zou, H.; Lu, D.; Gong, C.; Liu, Y. - Europ. Polym. J., 41, p.1554 (2005).

27. Dai, H.; Guan, R.; Li, C. \& Liu, J. - Solid State Ion., 178, p.339 (2007).

28. Chen, J.; Asano, M.; Yumaki, T. \& Toshida, M. - J. Power Sources, 158 , p.69 (2006).

29. Smitha, B.; Sridhar, S. \& Khan, A. A. - J. Memb. Sci., 225, p.63 (2003).

30. Devrim, Y.; Erkan, S.; Baç, N. \& Eroglu, I. - Hydrogen Energy, 34, p.3467 (2009).

31. Park, J.-S.; Choi, J.-H.; Woo, J.-J. \& Moon, S.-H. - J. Coll. Interf. Sci., 300, p.655 (2006).
32. Yuan, X.; Sun, J. C.; Blanco, M.; Wang, H. \& Zhang, J. - J. Power Sources, 161, p.929 (2006).

33. Iojoiu, C.; Dimitrova, P.; Maréchal, M. \& Sanchez, J.-Y. - Electroch. Acta, 51, p.4789 (2006).

34. Furtado, A. A. M. F. \& Gomes, A. S. - Inter. J. Polym. Mater., 59, p.424 (2010).

35. Kawahara, M.; Rikukawa, M.; Sanui, K. \& Ogata, N. - Solid State Ion., 136, p.1193 (2000).

36. Xing, P.; Robertson, G. P. \& Guiver, M. D. - J. Memb. Sci., 229, p.95 (2004).

37. Tsai, J-C.; Kuo, J-F.; Chen, C-Y. - J. Power Sources, 174, p.103 (2007).

38. Park, H. B.; Nam, S. Y.; Rhim, J. W.; Lee, J. M.; Kim, S. E.; Kim, J. R. \& Lee, Y. M. - J. Appl. Polym. Sci., 86, p.2611 (2002).

39. Chennamsetty, R.; Escobar, I. \& Xu, X. - Desalination, 188, p.203 (2006).

Enviado: 01/04/10

Reenviado: $24 / 08 / 10$

Aceito: $22 / 09 / 10$

DOI: $10.1590 /$ S0104-14282011005000024 